\section{Feedback Loops in the Politics of Knowledge Production}

\author{
by Troy Duster, New York University
}

The current debates about the role of race in the biological sciences, clinical genetics, and the allied fields of practical applications (pharmacogenomics and forensics) have generated a considerable amount of friction and heat. Adversaries tend to line up on one side or the other of the argument about the legitimacy, or lack of it, of the category of race. This is an unfortunate binary trap, and can be avoided if we can step back and look at the feedback loops between social and biological categories in the production of knowledge.

\section{Fluidity in the Scientific Status of the Concept of Race}

A consortium of leading scientists across the disciplines from biology to physical anthropology issued a "Revised UNESCO Statement on Race” in 1995 - a definitive declaration that summarizes eleven central issues, and concludes that in terms of "scientific" discourse, there is no such thing as a "race" that has any scientific utility:

\begin{abstract}
...the same scientific groups that developed the biological concept over the last century have now concluded that its use for characterizing human populations is so flawed that it is no longer a scientifically valid concept. In fact, the statement makes clear that the biological concept of race as applied to humans has no legitimate place in biological science (Katz 1995, p. 4, 5).
\end{abstract}

Note that the statement is not only about the utility of the concept of race for biological science. Rather, it asks in its title, "Is race a legitimate concept for science?" and in the quotation above, states that the concept "is so flawed that it is no longer a scientifically valid concept." For more than two centuries, the intermingling of scientific and common-sense thinking about race has produced remarkable trafficking back and forth between scientists and the laity, confusing for both laypersons and scientists about the salience of race as a stratifying practice (itself worthy of scientific investigation) versus race as a socially de-contextu- alized biologically accurate and meaningful taxonomy. The current decade is no exception. In the rush to purge common-sense thinking of groundless belief systems about the biological basis of racial classifications, the current leadership of scientific communities has overstated the simplicity of very complex interactive feedback loops between biology and culture and social stratification.

I will demonstrate how and why "purging science of race" - where race and ethnic classifications are embedded in the routine collection and analysis of data (from oncology to epidemiology, from hematology to social anthropology, from genetics to sociology) - is neither practicable, possible, nor even desirable. Rather, our task should be to recognize, engage and clarify the complexity of the interaction between any taxonomies of race and biological, neurophysiological, social, and health outcomes. Whether or not race is a legitimate concept for scientific inquiry depends upon the designation of the unit of analysis of "race", and will in turn be related to the purposes for which the concept is deployed. This may seem heretical at the outset, but may rescue an important role for examining the purpose of an investigation to legitimize the analytic utility of the concept of race.

My strategy will be threefold. First, I will summarize an emerging clinical genetics problem from recent blood studies that is now forcing scientific medicine to reconsider the practical or efficacious meaning of race when it comes to blood transfusions. Second, I will turn to recent attempts to identify individuals from ethnic and racial populations through the use of the new technologies of molecular genetics. Here it is vital to note the emphasis upon the practical applications of these technologies, from their uses in forensics (the exclusion or probable identification of suspects in criminal investigations) to pharmacogenomics - a field that explicitly deploys the concept of "race" in the attempt to focus the delivery of pharmaceuticals to populations so designated, and does not bother to place quotation marks around the concept. Third, I will briefly point to the possible, even likely interaction between racial or ethnic identity, nutritional intake, and biochemical manifestation of disease states, most notably, cancer and heart disease. Finally, I will suggest a way to address and even re- 
solve the confusing and contradictory messages about "race" from the biological sciences and their applied satellites.

I will conclude with some remarks about how anthropologists (and others working on aggregate data on selected populations designated by "race") should try to advance our understanding of how "race" is always going to be a complex interplay of social and biological realities with ideology and myth.

\section{Context and Content for Feedback Loops: Setting the Empirical Problem}

By the mid 1970s, it had become abundantly clear that there is more genetic variation within the most current common socially used categories of race than between these categories (Polednak 1989; Bittles and Roberts 1992; Chapman 1993; Shipman 1994). The consensus is a recent development. For example, in the early part of the twentieth century, scientists in several countries tried to link up a study of the major blood groups in the ABO system to racial and ethnic groups. ${ }^{1}$ They had learned that blood type $\mathrm{B}$ was more common in certain ethnic and racial groups - which some believed to be more inclined to criminality and mental illness (Gundel 1926; Schusterov 1927). They kept running up against a brick wall because there was nothing in the ABO system that could predict behavior. While that strategy ended a full half-century ago, there is a contemporary arena in which hematology, the study of blood, has had to resuscitate a concern with "race".

In the United States there has been an increasing awareness developed over the last two decades of the problem that blood from Americans of European ancestry (read mainly white) tends to contain a greater number of antigens than blood from Americans of African or Asian ancestry. This means that there is a greater chance for hemolytic reactions for blacks and Asians receiving blood from whites, but a lower risk for whites receiving blood from Asians or blacks. Here we come to a fascinating intersection between the biological and social sciences. In the United States, not only do whites comprise approximately 80 percent of the population, proportionally fewer blacks and fewer Asian Americans donate blood than do whites. This social fact has some biological consequences, which in turn have some social consequences.

This provides a remarkably interesting intersection. While the full range of analysts, commentators, and scientists - from postmodern essayists to molecular geneticists to social anthropologists - have been busily pronouncing "the death of race", for practical clinical purposes the concept is resurrected in the conflation of blood donation frequencies by "race". I am not merely trying to resurrect "race" as a social construct (with no biological meaning) - no more than I am trying to resurrect "race" as a biological construct with no social meaning. Rather, I am arguing that when "race" is used as a stratifying practice (which can be apprehended empirically and systematically) there is often a reciprocal interplay of a biological outcome that makes it impossible to completely disentangle the biological from the social. While that may be obvious to some, it is completely alien to others, and some of those "others" are key players in current debates about the biology of race.

In late September 1996, Tuskegee University hosted a conference on the Human Genome Project, with specific reference to the Project's relevance to the subject of race (Smith and Sapp 1997). In attendance was Luca Cavalli-Sforza, a pre-eminent population geneticist from Stanford University and perhaps the leading figure behind the Human Genome Diversity Project. ${ }^{2}$ Cavalli-Sforza had appeared on the cover of Time magazine a few years earlier, as something of a hero to the forces that were attacking the genetic determinism in The Bell Curve. ${ }^{3}$ At this conference, he repeated what he had said in the Time article: "One important conclusion of population genetics is that races do not exist” (ibid., p. 53).

If you take differences between two random individuals of the same population, they are about $85 \%$ of the differences you would find if you take two individuals at random from the whole world. This means two things: (1) The differences between individuals are the bulk of the variation; (2) the differences among populations, races, continents are very small the latter are only the rest, $15 \%$, about six times less than that between two random individuals of one perhaps very small population (85\%). Between you and your town grocer there is on average a variation which is almost 
as large as that between you and a random individual of the whole world. This person could be from Africa, China, or an Australian aborigine (ibid., p. 55).

Cavalli-Sforza is speaking here as a population geneticist, and in that limited frame of what is important and different about us as humans, he may be empirically correct. But humans give meaning to differences. At a particular historical moment, to tell this to an Albanian in Kosovo, a Hutu among the Tutsi, to a Zulu among the Boers, or to a German Jew among the Nazis, may be as convincing, for the purposes of further action, as telling it to an audience of mainly African Americans at Tuskegee University. ${ }^{4}$ Indeed, David Botstein, speaking later in a keynote address, had this to say about the Bell Curve:

So from a scientific point of view, this whole business of The Bell Curve, atrocious though the claims may be, is nonsense and is not to be taken seriously. People keep asking me why I do not rebut The Bell Curve. The answer is because it is so stupid that it is not rebuttable. You have to remember that the Nazis who exterminated most of my immediate family did that on a genetic basis, but it was false. Geneticists in Germany knew that it was false. The danger is not from the truth, the danger is from the falsehood. (ibid., p. 212)

\section{The American Anthropological Associa- tion Statement on "Race"}

In May 1998, the American Anthropological Association issued its own statement on "race" (1998). It attempts to address the myths and misconceptions, and in so doing takes a "corrective" stance towards the folk beliefs about race. The statement strongly states the position that "physical variations in the human species have no meaning except the social ones that humans put on them". But in casting "the problem" in this fashion, it gives the impression that the biological meanings that scientists attribute to race are biological facts, while the social meanings that laypersons give to race are first either errors or mere artificial social constructions, and second not themselves capable of feedback loops into the biochemical, neurophysiological, and cellular aspects of our bodies that, in turn, can be studied, scientifically. The statement of the Anthropological Associa- tion is consistent with that of the UNESCO statement on race. However, by formulating the matter so that it is "only the social meanings that humans provide" implies that mere lay notions of race provide a rationale for domination, but have no other utility.

There is profound misunderstanding of the implications of a "social contructivist" notion of social phenomena. How humans identify themselves, whether in religious or ethnic or racial or aesthetic terms, influences their subsequent behavior. Places of worship are socially constructed with human variations of meaning and interpretation and use very much in mind. Whether a cathedral or mosque, a synagogue or Shinto temple, those "constructions" are no less "real" because one has accounted for and documented the social forces at play that resulted in such a wide variety of "socially constructed" places of worship. "Race" as social construction can and does have a substantial effect on how people behave. One important arena for further scientific exploration and investigation is the feedback between that behavior and the biological functioning of the body. It is now appropriate to restate the well-known social analytic aphorism of W.I. Thomas, but to refocus it on human taxonomies of other humans: If humans define situations as real, they can and often do have real biological and social consequences.

\section{Explicating the Conflation of Crime, Ge- netics and Race}

If "race" is a concept with no scientific utility, what are we to make of a series of articles that have appeared in the scientific literature over the last seven years, looking for genetic markers of population groups that coincide with common-sense, lay renditions of ethnic and racial phenotypes? It is the forensic applications that have generated much of this interest. Devlin and Risch (1992a) published an article on "Ethnic differentiation at VNTR loci, with specific reference to forensic applications" - a research report that appeared prominently in the American Journal of Human Genetics.

The presence of null alleles leads to a large excess of single-band phenotypes for blacks at D17S79.... This phenomenon is less important for the Caucasian and Hispanic popu- 
lations, which have fewer alleles with a small number of repeats (p. 540)

...it appears that the FBI's data base is representative of the Caucasian population. Results for the Hispanic ethnic groups, for the D17S79 locus, again suggest that the data bases are derived from nearly identical populations, when both similarities and expected biases are considered.... For the allele frequency distributions derived from the black population, there may be small differences in the populations from which the data bases are derived, as the expected bias is .05. (p. 546)

The work of Devlin and Risch (1992a, 1992b), Evett et al. (1993, 1996) and others suggest that there are only about 10 percent of sites in the DNA that are "useful" for making distinctions. This means that at the other 90 percent of the sites, the allele frequencies do not vary between groups such as "Afro-Caribbean people in England" and "Scottish people in England". But it does not follow that because we can not find a single site where allele frequency matches some phenotype that we are trying to identify (for forensic purposes, we should be reminded), that there are not several (four, six, seven) that will not be effective, for the purposes of aiding the FBI, Scotland yard, or the criminal justice systems around the globe in highly probabilistic statements about suspects, and the likely ethnic, racial, or cultural populations from which they can be identified - statistically.

An article in the 8 July 1995 issue of the New Scientist entitled "Genes in black and white" details some extraordinary claims made about what it is possible to learn about socially defined categories of race from reviewing information gathered using new molecular genetic technology (Vines 1995):

In 1993, a British forensic scientist published what is perhaps the first DNA test explicitly acknowledged to provide "intelligence information" along "ethnic" lines for "investigators of unsolved crimes". Ian Evett, now at the Home Office's forensic science laboratory in Birmingham, and his colleagues in the Metropolitan Police, claim that their DNA test can distinguish between "Caucasians" and "AfroCaribbeans" in nearly 85 percent of the cases.... Evett's work, published in the Journal of Forensic Science Society, draws on apparent genetic differences in three sections of human DNA. Like most stretches of human DNA used for forensic typing, each of these three regions differs widely from person to person, irrespective of race. But by looking at all three, say the researchers, it is possible to estimate the probability that someone belongs to a particular racial group.

The implications of this for determining, for legal purposes, who is and who is not "officially" a member of some racial or ethnic category are profound.

Two years after the publication of the UNESCO statement purportedly burying the concept of "race" for the purposes of scientific inquiry and analysis, and during the same time period that the American Anthropological Association was deliberating and generating a parallel statement, an article appeared in the American Journal of Human Genetics, authored by Ian Evett and his associates, summarized thusly:

Before the introduction of a four-locus multiplex short-tandem-repeat (STR) system into casework, an extensive series of tests were carried out to determine robust procedures for assessing the evidential value of a match between crime and suspect samples. Twelve databases were analyzed from the three main ethnic groups encountered in casework in the United Kingdom; Caucasians, Afro-Caribbeans, and Asians from the Indian subcontinent. Independence tests resulted in a number of significant results, and the impact that these might have on forensic casework was investigated. It is demonstrated that previously published methods provide a similar procedure for correcting allele frequencies - and that this leads to conservative casework estimates of evidential value. (Evett et al. 1996, p. 398)

These new technologies have some not-sohidden potential to be used for a variety of forensic purposes in the development and "authentication" of typologies of human ethnicity and race. A contemporary update of an old idea of the idea of deciding upon "degree of whiteness" or "degree of nativeness" is possibly upon us, anew, with the aid of molecular genetics. Vines (1995) describes the Allotment Act of 1887, denying land rights to those native Americans who were "less than half-blood". The U.S. government still requires American Indians to produce "Certificates with Degree of Indian Blood" in order to qualify for a number of entitlements, including being able to have one's art so labeled. The Indian Arts and Crafts Act of 1990 made it 
a crime to identify oneself as a Native American when selling artwork without federal certification authorizing one to make the legitimate claim that one was, indeed, an authentic ("onequarter blood" even in 1990s) American Indian. As noted above, it is not art, but law and forensics that ultimately will impel the genetic technologies to be employed on behalf of attempts to identify who is "authentically" in one category or another. Geneticists in Ottawa, Canada have been trying to set up a system "to distinguish between 'Caucasian Americans' and 'Native Americans' on the basis of a variable DNA region used in DNA fingerprinting" (Vines 1995, p. 37). For practical purposes, the issue of the authentication of persons' membership in a group (racial/ethnic/cultural) can be brought to the level of DNA analysis. The effectiveness of testing and screening for genetic disorders in risk populations that are ethnically and racially designated poses a related set of vexing concerns for the "separation" of the biological and cultural taxonomies of race.

\section{Genetic Testing and Genetic Screening}

When social groupings with a strong endogamous tradition (such as ethnic or racial groups) intermarry for centuries, they are at higher risk for pairing recessive genes and passing on a genetic disorder. In the United States, the best knowns of these clustered autosomal recessive disorders are Tay-Sachs disease, beta-thalassemia, sickle-cell anemia, and cystic fibrosis. For Tay-Sachs, concentrated primarily among Ashkenazi Jews of northern and eastern European ancestry, about one in thirty is a carrier, and approximately one in every 3,000 newborns will have the disorder. For cystic fibrosis, about one in thirty Americans of European descent is a carrier, with a similar incidence rate. In contrast, approximately one in every 12 American blacks is a carrier for sickle-cell anemia and one in every 625 black newborns will have the disorder. Irish and northern Europeans are at greater risk for phenylketonuria. In the United States, one in 60 Caucasians is a carrier, and about one in every 12,000 newborn Caucasians is affected (Detailed information on the Incidence of Genetic Disorders can be found in Burhansstipanov et al. 1987, p. 6-7).
When both parents are carriers of the autosomal recessive gene, the probability that each live birth will be affected by the disorder is 25 percent. However, being a carrier, or passing on the gene so that one's offspring is also a carrier, typically poses no more of a health threat than carrying a recessive gene for a different eye color. That is, carrier status typically poses no health threat at all. The health rationale behind carrier screening is to inform prospective parents about their chances of having a child with a genetic disorder.

In the United States, the two most widespread genetic screening programs for carriers have been for Jews of northern European descent (Tay-Sachs) and for Americans of western African descent (sickle-cell anemia). From 1972 to 1985, there was widespread prenatal screening for both disorders, and by 1988, newborn screening for sickle-cell anemia had become common (Duster 1990). It is the autosomal recessive disorders, located in risk populations that coincide with ethnicity and race, that are of special interest as we turn to address genetic screening for populations that are at greatest risk for a disorder.

It is important to distinguish between a genetic screen and a genetic test. A genetic test is done when there is reason to believe that a particular individual is at high risk for having a genetic disorder, or for being a carrier of a gene (recessive) for a disorder. So for example, a sibling of someone who has been diagnosed with Huntington's (a late-onset neurological disorder) would be a candidate for a genetic test for that disorder. A genetic screen, on the other hand, is used for a population that is at higher risk for a genetic disorder. Thus, with the risk figures cited above, Ashkenazi Jews were the subjects of genetic screening for Tay-Sachs.

\section{The Interaction between Race as Identity, Nutrient Consumption, and Health}

The scientific literature on the rates of specific cancers in racially and ethnically designated populations is fairly well-developed. For example, Ashkenazic Jewish women are reported, clinically, to have higher rates of breast cancer than other groups. African-American men have almost double the rate of prostate cancer of white men in certain age groups, according to 
reports released by the National Cancer Institute (Ries et al. 2002). How might this be explained, using race not simply as an "outcome" - but as a factor that helps produce the outcome? Consider the possibility that certain forms of cancer may be a function of nutrition and diet. Groups with certain dietary patterns or restrictions might then be systematically (i.e., apprehensive scientifically) at greater risk for cancer. If members of a certain group identify themselves as say, Ashkenazic Jewish, and then have a diet that follows certain patterns, they might well routinely have rates of certain groups of cancers, at both lower and higher risks than groups with different dietary habits. African American males, for example, may, by identifying as African Americans, be more likely to eat a category of food ("soul food") that might systematically put them at higher risk for prostate cancer. With this formulation, I am "bringing the systematic study of race" back into the "scientific inquiry" - even though I am not going to the molecular level to attempt a reductionist account of "race as caused" at the level of the DNA.

Here is where the computer revolution enters the story: Up until very recently, we could not do much with these random variations in the DNA, called single nucleotide polymorphisms - SNPs. However, with the new computers, we can now put the DNA of several clusters of people on computer chips, and see what might be patterns in their DNA (Hamadeh and Afshari 2000).

It is now possible to do hundreds, even thousands of experiments in a few hours. This might prove to be a useful technology in the hunt for particular regions that might help explain some illnesses. For example, if we get a few hundred patients, all with prostate cancer then look at their SNP profiles using this chip technology. Or perhaps with heart disease, a similar strategy.

With these new SNPs on chips, we will come up with new taxonomies of people who share certain kinds of patterns in their DNA, and who suffer from the same illness

Even with strong epidemiological evidence that heart disease and hypertension among African Americans is strongly associated with such social factors as poverty, there has been a persistent attempt to pursue the scientific study of hypertension through a link to the genetics of race. Dark pigmentation is indeed associated with hypertension in America. Michael Klag et al. (1991) reported the results of a carefully controled study looking at the relationship between skin color and high blood pressure. He and his colleagues found that darker skin color is a good predictor of hypertension among blacks of low socioeconomic status, but not for blacks of any shade who are "well employed or better educated". The study further suggested that poor blacks with darker skin color experience greater hypertension "not for genetic reasons" but because darker skin color subjects them to greater discrimination, with consequently greater stress and psychological/medical consequences. Of course, from another way of looking at it, "darker skin color" is dark mainly for genetic reasons, so it is all a matter of how one chooses to direct theorizing about the location of causal arrows. When practicing physicians see "darker skin color," their diagnostic interpretation and their therapeutic recommendations are systematically affected. Schulman et al. (1999) recently published some research indicating that in clinical practice, physicians are likely to make systematically different recommendations for treatment of heart disorders, by race, even when patients present the same symptoms. Thus, when there is an analysis of outcome data such as "cause of death" by race, and researchers find that blacks have a higher incidence of death from heart failure - it would be easy to make an incorrect inference about causation and direction of the relationship between the variables.

By heading toward an unnecessarily binary, socially constructed fork in the road, by forcing ourselves to think that we must either choose between either "race as biological" (now out of favor) and "race as merely a social construction" we fall into an avoidable trap. A refurbished and updated insight from W. I. Thomas can help us. It is not an either/or proposition. Under some conditions, we need to conduct systematic investigation, guided by a body of theory, into the role of "race" (or ethnicity, or religion) as an organizing force in social relations, and as a stratifying practice (Oliver and Shapiro 1995). Under other conditions, we will need to conduct systematic investigation, guided by a body of theory, into the role of the interaction of "race" (or ethnicity, or religion) 
however flawed as a biologically discrete and coherent taxonomic system, with feedback loops into the biological functioning of the human body; or with medical practice. The latter studies might include examination of the systematic administration of higher doses of $\mathrm{x}$ rays to African Americans; the creation of genetic tests with high rates of sensitivity to some ethnic and racial groups, but low sensitivity to others; and the systematic treatment, or lack of it, with diagnostic and therapeutic interventions to "racialized" heart and cancer patients.

It is not difficult to understand why they persisted. Humans are symbol-bearing creatures that give meaning to their experiences and to their symbolic worlds. The UNESCO statement is ultimately about the problem of the difference between first-order constructs in science, versus second-order constructs. Some fifty years ago, Felix Kaufmann ([1944] 1958) made a crucial distinction that throws some light on the controversy. Kaufmann was not addressing whether or not there can be a science of race. Rather, he noted that there are different kinds of issues, methodologies, and theories that are generated by what could be called "first-order constructs" in the physical and natural sciences versus "second-order constructs." For the physical and natural sciences, the naming of objects for investigation and inquiry, for conceptualizing and finding empirical regularities, is in the hands of the scientists and their scientific peers. Thus, for example, the nomenclature for quarks or neurons, genes or chromosomes, nitrogen or sulfides, etc., all reside with the scientist in his/her role as the creator of first-order constructs.

This is quite different from the task of the observer, analyst, or scientist of human social behavior. This is because humans live in a preinterpreted social world. They grow up, from infancy, in a world that has pre-assigned categories and names for those categories, which were in turn provided by fellow common-sense actors, not by "scientists" (Schutz 1973). Their continual task is to try to navigate, negotiate and make sense of that world. The task of the social scientist is therefore quite distinct from that of the natural scientist. While the latter can rely upon "first-order constructs", the former must construct a set of categories based upon the preinterpreted world of common-sense actors. The central problem is that "race" is now, and has been since $1735,{ }^{5}$ both a first- and second-order construct. The following joke, making the rounds among African-American intellectuals, makes the point with deft humor:

'I have noted', the joke laments, 'that my research demonstrating that race is merely a social and ideological construction helps little in getting taxis to pick me up late at night'.

This throws into a different light the matter of whether race can be studied scientifically. If we mean by that, is there a consensus among the natural scientists about race as a "first-order construct", then the answer since about 1970 is categorically "no". The UNESCO statement summarizes why this is so at every level that is significant to the biological functioning of the organism, with two exceptions. We have already noted that scientific research on first-order constructs about race as a biological category in science in the last four decades has revealed over and over again that there is greater genetic heterogeneity within versus between major racial groupings (Polednak 1989; Bittles and Roberts 1992; Chapman, 1993; Shipman 1994). One exception is that the gene frequencies, as demonstrated in the use of specific polymorphic markers, occur more frequently in certain populations than in others. But this distribution of gene frequencies, though occasionally overlapping with racial groupings, is definitively not only a racially defined issue. For example northern Europeans have greater concentrations of cystic fibrosis than southern Europeans, and both are categorized as "Caucasians". Moreover, southern Europeans have higher rates of betathalassemia than northern Europeans - but even more to the point, sickle-cell anemia is found in greater concentration in Orchomenos, Greece, than among African Americans (Duster 1990). This is not a biologically racially defined matter (i.e., racial in the sense of first-order constructs).

\section{Race and "Second-Order Constructs"}

Financially, the biggest difference between whites and African Americans today is their median net worth, which is overwhelmingly attributable to the value of equity in housing stock. In 1991, the median net worth of white households $(\$ 43,279)$ was more than 10 times that of the 
median net worth of African-American households (\$4,169, Bureau of the Census 1991). This is a truth that can be determined by the systematic collection of empirical data, and either replicated or refuted - which is to say that it can be investigated scientifically, without reference to blood groups, the relationship between genotype and phenotype, or the likelihood that one group is more likely to be at risk for cystic fibrosis while the other is more likely to be at risk for sickle-cell anemia. Here is why:

In 1939, the Federal Housing Authority's Underwriting Manual that provided the guides for granting housing loans explicitly used race as one of the most important criteria. The manual stated that loans should not be given to any family that might "disrupt the racial integrity" of a neighborhood. Indeed, the direct quote from Section 937 of the FHA manual went so far as to say that "If a neighborhood is to retain stability, it is necessary that properties shall be continued to be occupied by the same social and racial classes" (Massey and Denton 1993, p. 54). On this basis, for the next thirty years, whites were able to get housing loans at 3-5 percent, while Blacks were routinely denied such loans. For example, of 350,000 new homes built in Northern California between 1946 and 1960 with FHA support, fewer than 100 went to blacks. That same pattern holds for the whole state, and for the nation as well.

To throw out the concept of race is to take the non-thinking alternative - the ostrich approach to race and ethnicity, pioneered and celebrated by the French government: "We don't collect data on that topic. Therefore, it does not exist!" 6 Or perhaps the legacy of Sapir and Whorf where language limits thinking is alive and well in the scientific study of race.

\section{Notes}

1) For the discussion in this paragraph, and for the references to the German literature that are used here, I am indebted to William H. Schneider (1996).

2) The Human Genome Diversity Project is not to be confused with the Human Genome Project. The latter is a \$ 3-billion effort, jointly funded in the United States by the National Institutes of Health and the Department of Energy. The goal is to map and sequence the entire human genome, and the major rationale for the project, from the outset approximately a decade ago, was to provide information that would assist medical genetics in de-coding, better understanding, and eventually, hopefully producing gene therapeutic interventions for genetic disorders. In contrast, the Human Genome Diversity Project has been concerned with tracing human populations through an evolutionary history of many centuries. Its goal was primarily to better understand human evolution (Committee on Human Genome Diversity 1997).

3) This was a popular book by Richard Herrnstein and Charles Murray (1994).

4) Tuskegee, after all, was the site of the infamous syphilis experiments on black males - where the Public Health Service of the U.S. Government had studied the racial effects of how the disease ravages the body of blacks in contrast to whites (Jones 1981).

5) This was the year that Linnaeus published System Naturae, in which he revealed a four-part classification scheme of the human races that has residues still today.

6) Perhaps an internally consistent emanation from a society that gave the world the Cartesian formulation about thought and existence - and subject/object dualities.

\section{References}

American Anthropological Association, 1998: American Anthropological Association statement on 'race'. American Anthropologist 100(3), p. 712-13

Bittles, A.H.; Roberts, D.F. (eds.), 1992: Minority Populations: Genetics, Demography and Health. London: Macmillan

Burhansstipanov, L., Giarratano, S.; Koser, K.; Mongoven, J., 1987: Prevention of Genetic and Birth Disorders. Sacramento: California State Department of Education, p. 6-7

Chapman, M. (ed.), 1993: Social and Biological Aspects of Ethnicity. New York: Oxford University Press

Committee on Human Genome Diversity, 1997: Scientific and Medical Value of Research on $\mathrm{Hu}-$ man Genetic Variation. In: Evaluating Human Genetic Diversity. National Research Council. Washington, D.C.: National Academy Press, p. 16-22

Devlin, B.; Risch, N., 1992a: Ethnic differentiation at VNTR loci, with specific reference to forensic applications. American Journal of Human Genetics 51, p. $534-48$

Devlin, B.; Risch, N., 1992b: A note on the HardyWeinberg equilibrium of VNTR data by using the Federal Bureau of Investigation's fixed-bin method. American Journal of Human Genetics 51, p. 549-53 
Duster, T., 1990: Backdoor to Eugenics. New York: Routledge

Evett, I.W., 1993: Criminalistics: The future of expertise. Journal of the Forensic Science Society 33(3), p. 173-8

Evett, I.W., Gill, P.D.; Scranage, J.K.; Wier, B.S., 1996: Establishing the robustness of short-tandemrepeat statistics for forensic application. American Journal of Human Genetics 58, p. 398-407

Evett, I.W.; Buckleton, I.S.; Raymond, A.; Roberts, H., 1993: The evidential value of DNA profiles. Journal of the Forensic Science Society 33(4), p. 243-4

Gundel, M., 1926: Einige Beobachtungen bei der rassenbiologischen Durchforschung SchleswigHolsteins. Klinische Wochenschrift 5, p. 1186

Hamadeh, H.; Afshari, C.A., 2000: Gene chips and functional genomics. American Scientist 88(6), p. 508-15

Herrnstein, R.J.; Murray, C., 1994: The Bell Curve: Intelligence and class structure in American life. New York: The Free Press

Jones, J.H., 1981: Bad Blood: The Tuskegee syphilis experiment: A tragedy of race and medicine. New York: The Free Press

Katz, S.H., 1995: Is race a legitimate concept for science? The AAPA Revised Statement on Race: A Brief Analysis and Commentary, University of Pennsylvania, February

Kaufmann, F., [1944] 1958: Methodology of the Social Sciences. New York: Humanities Press

Klag, M.; Whelton, P.K.; Coresh, J.; Grim, C.E.; Kuller, L.H., 1991: The association of skin color with blood pressure in U.S. blacks with low socioeconomic status. Journal of the American Medical Association 265(5), p. 599-602

Massey, D.S.; Denton, N.A., 1993: American Apartheid: Segregation and the Making of the Underclass. Cambridge, MA: Harvard University Press

Oliver, M.L.; Shapiro, Th.M., 1995: Black Wealth/ White Wealth: A new perspective on racial inequality. New York: Routledge

Polednak, A.P., 1989: Racial and Ethnic Differences in Disease. New York, N.Y.: Oxford University Press

Ries, L.A.G.; Eisner, M.P.; Kosary, C.L.; Hankey, B.F.; Miller, B.A.; Clegg, L.; Edwards, B.K. (eds.), 2002: SEER Cancer Statistics Review, 1973-1999, National Cancer Institute. Bethesda, MD. Table XXII-1

Schneider, W.H., 1996: The history of research on blood group genetics: Initial discovery and diffusion. History and Philosophy of the Life Sciences 18(3), p. 277-303
Schulman, K.A.; Berlin, J.A.; Harless, W.; Kenner, J.F.; Sistrunk, S.; Gersh, B.J.; Dube, R.; Taleghani, C.K.; Burke, J.E.; Williams, S.; Eisenberg, J.M.; Escarce, J.J., 1999: The effect of race and sex on physicians' recommendations for cardiac catheterization. New England Journal of Medicine 34(8, February 25), p. 618-26

Schusterov, G.A., 1927: Isohaemoagglutinierenden Eigenschaften des menschlichen Blutes nach den Ergebnissen einer Untersuchung an Sträflingen des Reformatoriums (Arbeitshauses) zu Omsk. Moskovskii Meditsinksii Jurnal 1, p. 1-6

Schutz, A., 1973: Common Sense and Scientific Interpretation of Human Action. In: Collected Papers I: The Problem of Social Reality, edited and introduced by Maurice Natanson (The Hague: Martinus Nijhoff)

Shipman, P., 1994: The Evolution of Racism: Human differences and the use and abuse of science. New York: Simon and Schuster

Smith, E., Sapp, W. (eds.), 1997: Plain Talk About the Human Genome Project. Tuskegee, Ala: Tuskegee University

Vines, G., 1995: Genes in black and white. New Scientist 147(8 July), p. 34-7

\section{Contact}

Troy Duster, Director Institute for the History of the Production of Knowledge Professor of Sociology, New York University 285 Mercer Street, 10th Floor New York, NY 10003-6653, USA

Tel.: +1 - 212 - 998 - 8882

Fax: +1 - 212 - 995 - 4904

E-Mail: troy.duster@nyu.edu 